\title{
Wish to Die and Physical Illness in Older Adults*
}

\author{
Sylvie Lapierre, Sophie Desjardins \\ Université du Québec à Trois-Rivières, \\ Canada
}

\author{
Michel Préville \\ Université de Sherbrooke, Research Center of \\ Charles-Lemoyne Hospital, Canada
}

\author{
Djamal Berbiche \\ Research Center of \\ Charles-Lemoyne Hospital, \\ Canada
}

\author{
Lyson Marcoux, Micheline \\ Dubé \\ Université du Québec à \\ Trois-Rivières, Canada
}

\begin{abstract}
The wish to die is the first step into the suicidal process. While depression is a major risk factor for the wish to die in old age, it seems that chronic physical illness could also be an important associated factor. Therefore, it would be interesting to look at the relations between 15 specific illnesses and the wish to die in old age. A representative probabilistic sample of community-dwelling older adults aged over $65(M=73.9)$ took part in a large survey on the prevalence of mental disorders, that also gathered information on chronic illness. Results indicated that $5.2 \%$ of the 2,811 respondents believed that they would be better dead, and that nine types of chronic illnesses were found significantly more often in elderly persons with the wish to die compared to those without. A logistic regression, including these nine diseases, revealed that, when gender was controlled for, three types of chronic illnesses were significantly associated with increased odds of wish to die: arthritis/rheumatism $(\mathrm{OR}=1.72)$, respiratory problems $(\mathrm{OR}=1.85)$, and urinary/prostate disorders $(\mathrm{OR}=1.76)$. Although many chronic illnesses were found significantly more often in persons with a wish to die, painful diseases causing functional limitations (arthritis) and illnesses that affect basic physiological needs (breathing, eliminating) were particularly important associated factors. New research should look at the possible mediating effects of helplessness, hopelessness, perceived burdensomeness, and reduced quality of life on the relation between chronic illness and the wish to die.
\end{abstract}

Keywords: wish to die, suicide, depression, quality of life, chronic illness

\section{Introduction}

With declining health, older adults face many challenges that require increased adaptation to various changes in their life (Fiksenbaum, Greenglass, \& Eaton, 2006; Freund, 2008). Those who cannot deal with the transformations and losses associated with chronic illness, sometimes think that life is a burden, without value

\footnotetext{
* Acknowledgements: This study was supported by the Canadian Institute of Health Research (200403MOP).

Sylvie Lapierre, Ph.D., full professor, Department of Psychology, Université du Québec à Trois-Rivières. Sylvie.Lapierre@uqtr.ca

Sophie Desjardins, Ph.D., full professor, Department of Psychology, Université du Québec à Trois-Rivières.

Michel Préville, Ph.D., full professor, Department of Community Health Sciences, Université de Sherbrooke.

Djamal Berbiche, Ph.D., senior statistician, Department of Community Health Sciences, Université de Sherbrooke.

Lyson Marcoux, M.A., assistant professor, Department of Psychology, Université du Québec à Trois-Rivières.

Micheline Dubé, Ph.D., retired professor, Department of Psychology, Université du Québec à Trois-Rivières.
} 
and meaning, and wish for death (Kjølseth, Ekeberg, \& Steihaug, 2010). Wishes to die constitute the first step into the process toward suicide. The concept of suicidality includes all cognitive and behavioral manifestations related to the suicidal process: wishes to die, suicidal ideations, self-harm, indirect self-destructive behaviors, suicidal plans and attempts, as well as completed suicide (Marušič, 2004; O'Connell, Chin, Cunningham, \& Lawlor, 2004; Scocco \& De Leo, 2002). The complexity and fluctuation of the process make it difficult for health professionals to identify suicidal individuals (De Leo, Cerin, Spathonis, \& Burgis, 2005). Wishes to die should be studied because they represent a unique opportunity for early detection and intervention of vulnerable individuals (Heisel, Duberstein, Talbot, King, \& Tu, 2009) and because of their association with depression (Linden \& Barnow, 1997), which is a major risk factor for suicide in old age (Harwood, Hawton, Hope, Harriss, \& Jacoby, 2006). Therefore, to prevent elderly suicide, it is important to look at predictors of death wishes, especially since psychological autopsies showed that older adults who committed suicide expressed their wish to die for some time before their death (Kjølseth et al., 2010).

Wishes to die are fairly common in older adults living in the community, a prevalence of $4 \%$ to $7 \%$, while suicidal ideations are rarer, varying between $1 \%$ and $2 \%$ in Western countries (Ayalon \& Shiovitz-Ezra, 2011; Barnow \& Linden, 2000; Kim, Bogner, Brown, \& Gallo, 2006; Lapierre et al., 2012; Scocco \& De Leo, 2002). For example, Barnow and Linden (2000) found that $14.7 \%$ of adults aged over $70(N=516)$ felt that life was not worth living, $5.4 \%$ wished to be dead, and $1 \%$ had suicidal ideas. In their sample of 611 Italians over 65 , living in the community, Scocco and De Leo (2002) observed a prevalence of $4.2 \%$ for the wish to die, $2.1 \%$ for suicidal thoughts, $0.7 \%$ for serious suicidal intentions, and $0.014 \%$ for attempts, during the last year. The prevalence of the wish to die was slightly higher $(6.1 \%)$ in a study with elderly patients treated by primary health care services (Kim et al., 2006). While in a sample $(N=125)$ of adults over 80 years $(M=86.1)$, Rao, Dening, Brayne, and Huppert (1997) noted a lack of the will to live in $5 \%$, a weak desire to live in $11 \%$, a strong wish to die in $16 \%$, and the wish to end it all (last two years) in $7 \%$. Rurup and colleagues suggested that the next studies should take into account the four dimensions that contribute to the development of the wish to die in elderly adults who face a situation they find unacceptable: (1) negative aspects of living; (2) positive aspects of dying; (3) negative aspects of dying; and (4) positive aspects of living (Rurup, Pasman, Goedhart, Deeg, Kerkhof, \& Onwuteaka-Philipsen, 2011). However, to our knowledge, there is no measure of these different dimensions of the wish to die. Completed suicides are significantly more frequent in men than women (Préville, Hébert, Boyer, Bravo, \& Seguin, 2005), but wishes to die are reported by women twice more than by men (Lapierre et al., 2012; Saïas, Beck, Bodard, Guignard, \& Roscoät, 2012; Scocco, Meneghel, Caon, Buono, \& De Leo, 2001; Vasiliadis, Gagné, \& Préville, 2012). For example, results from the European Survey on Health, Ageing, and Retirement $(N=11,425)$ showed a prevalence of $6.9 \%$ of wishes to die in men and $13 \%$ in women (Saïas et al., 2012). As for age, it seems that wishes to die are expressed more frequently by adults over $75(15.6 \%)$ than by those between 66 and 75 years (7.3\%), and those between 50 and 65 years (4.6\%) (Ayalon \& Shiovitz-Ezra, 2011).

Most studies have shown that depression is a major risk factor for suicide in old age (Préville et al., 2005) and an important associated factor of the wish to die (Rurup, Deeg, Poppelaars, Kerkhof, \& Onwuteaka-Philipsen, 2011). Skoog et al. (1996) indicated that, in older adults over 85 years with mental health problems, $27.5 \%$ wished to die and $9.2 \%$ had suicidal ideations, compared with $4 \%$ and $0.9 \%$ respectively in older adults in good mental health. Physical illness also seems to be a risk factor for suicidality. However, only 
a few studies looked precisely at the relationship of illness with the wish to die in seniors. They showed that poor self-rated physical health, disability, pain, hearing and visual impairment, as well as chronic medical conditions (myocardial infarction, stroke, urinary incontinence, falls within the past six months) were associated with the wish to die (Jorm, Henderson, Scott, Korten, Christensen, \& Mackinnon, 1995; Kim et al., 2006). More recently, Saïas et al. (2012) showed that having a long-term illness or disability was significantly associated with wishes to be dead, even when controlling for depression in the multivariate analysis $(\mathrm{OR}=1.28$, $\left.\mathrm{CI}_{95 \%}=1.07-1.53 ; p=0.008\right)$.

These results are similar to those that found that serious physical illnesses, particularly those causing functional limitation and chronic pain, were reported as significant risk factors for suicidal ideations and suicide among older adults, when depression was controlled (Awata et al., 2005; Bonnewyn et al., 2009; Harwood et al., 2006; Juurlink, Herrmann, Szalai, Kopp, \& Redelmeier, 2004; Meeks et al., 2008; Rubenowitz, Waern, Wilhelmson, \& Allebeck, 2001; Waern, Rubenowitz, Runeson, Skoog, Wilhelmson, \& Allebeck, 2002; Waern, Rubenowitz, \& Wilhelmson, 2003). Moreover, a Korean study, which examined the causes of 31,711 completed suicides between 2004 and 2006, observed that physical illness was a triggering factor (the most recent event before a suicide) in more than $50 \%$ of suicides in adults aged 70 and over (Im, Choi, Hong, Seo, Park, \& Hong, 2011). Only a few studies looked at specific illnesses and their relations with suicidality in older adults. Juurlink et al. (2004) found that suicide was associated with congestive heart problems, chronic obstructive lung diseases, seizure disorders, and urinary incontinence. In a case-control study, Quan, Arboleda-Florez, Fick, Stuart, and Love (2002) found that Canadians over 55 who suffered from cancer, ischemic heart disease, chronic pulmonary disease, peptic ulcer, prostatic disorder, were at increased risk of suicide, compared to controls who died in a motor vehicle accident.

Most studies on the relationship between suicide and physical illness used the psychological autopsy method or records from the medical examiner's office to get their results. There is a lack of research that directly asks older adults about their suicidal ideations and even less about their wish to die. Therefore, this research had three objectives: first, to study the prevalence of the wish to die in older adults living in the community; second, to identify which chronic illness differentiates those with the wish to die from those without, and finally, to verify the hypothesis that certain types of illnesses are important associated factors, even when depression is controlled.

\section{Method}

\section{Procedure and Sample}

Data used in this research were taken from a large survey (the ESA study) on the annual prevalence of mental disorders in the older adult population (Préville et al., 2008), that also gathered information on many types of physical illnesses. The ESA study used a probabilistic sample of French speaking community-dwelling older adults from each of the 16 administrative regions of the province of Quebec in Canada. A random-digit dialing method was applied to develop the sampling frame of the study which included stratification according to three geographical areas: (1) metropolitan, (2) urban, and (3) rural. Only one older adult (65 years and over) was selected within the household.

Data were collected by health professionals $(N=20)$, staff members of a national polling firm, who contacted the potential respondents and asked them to participate. A letter describing the study was also sent to them, and appointments were made with those who volunteered. Participants were interviewed at home within 
two weeks of initial contact. The response rate for this study was $76.5 \%$. The Mini-Mental State Examination (M. F. Folstein, S. E. Folstein, \& McHugh, 1975) was completed at the beginning of the interview, and participants who scored below 22, indicating severe or moderate cognitive problems (Crum, Anthony, Bassett, \& Folstein, 1993), were excluded from the sample because of their inability to answer questions accurately. All other participants responded to the additional questionnaires. On average, the duration of the interview was 90 minutes.

The sample (see Table 1) included 2,811 old adults aged between 65 and 98 years $(M=73.9 ; S D=5.7)$ who were living at home. Most of the participants (70.4\%) were women. About half of the respondents were not in a marital relationship (54.7\%), while $45.7 \%$ reported an annual income lower than 25,000 \$CDN. A third of the sample lived in a metropolitan area $(35.7 \%), 33.8 \%$ in a rural region, and $30.5 \%$ in a small urban community. As for the level of education, $24.4 \%$ had less than seven years of schooling, $41.8 \%$ had between eight and 12 years, and $33.8 \%$ had 13 years or more.

\section{Measures}

The wish to die was identified with the following question: "During the last 12 months, did you have a period of at least two weeks, when you thought that you would be better dead?" Many studies do not distinguish wishes to die and suicidal ideations. Because some chronic illnesses could be associated with wishes to die and others with suicidal ideations, the present sample excluded participants who also expressed suicidal ideations by answering "Yes" to the following question: "During the last 12 months, did you have a period of at least two weeks, when you seriously thought about committing suicide or taking your own life?" All respondents were given contact phone numbers of various mental health resources and professionals in their region in order to get help, if needed. The research procedure was previously reviewed and authorized by the ethics committee of the Sherbrooke Geriatric University Institute.

The respondent's mental health status was measured using the ESA Diagnostic Questionnaire (developed in French), which gives a 12-month period diagnosis of major psychiatric disorders based on the DSM-IV criteria (Préville et al., 2008). For the purpose of the present study, only diagnoses concerning major and minor depression were considered. The presence of various chronic health problems was documented with the list of the International Classification of Diseases. The survey included a list of 15 chronic illnesses. Participants answered the following question: "To your knowledge and according to a doctor, do you have one of the following illnesses: anemia, arthritis/rheumatism, back problem, blood pressure, cholesterol, diabetes, digestive problem, endocrine problem, heart problem, kidney/urinary/prostate problem, liver problem, migraine/headaches, respiratory problem, skin problem, visual problem (glaucoma or cataract)". The respondents also rated their physical health, by comparing it to people at their own age, on a Likert scale ranging from 1 ("Excellent") to 5 ("Bad").

\section{Statistical Analyses}

First, bivariate analyses $\left(\chi^{2}\right.$ or $t$-tests) were used to determine the differences in socio-demographic characteristics, depression, and frequency of various chronic illnesses, between older adults with and without the wish to die. Second, two multinomial logistic regression analyses were employed to describe the associations between chronic illnesses and the respondents' wish to die status: The first one adjusted for gender and the second one adjusted for depression and gender. The odds ratio and confidence intervals (95\%) were computed as a measure of association. 


\section{Results}

Results indicated that 145 respondents thought that they would be better dead. The prevalence of the wish to die is estimated at $5.2 \%\left(\mathrm{CI}_{95 \%}\right.$ : 4.6-6.4). Table 1 shows that there were significant differences between respondents with the wish to die and those without, on gender, marital status, level of education, and income. Among those with the wish to die, there was a significantly higher proportion of women $(80.7 \%$ vs $69.8 \%$ among those without the wish to die), unmarried (single, widowed, separated/divorced) respondents (64.8\% vs $54.1 \%)$, persons with less than 13 years of education $(75.2 \%$ vs $65.7 \%)$, or an income lower than $25,000 \$ C D N$ (55.6 vs $45.1 \%)$. There was no significant difference on age.

Table 1

Differences Between Participants With and Without the Wish to Die $(N=2,811)$

\begin{tabular}{|c|c|c|c|c|c|c|c|}
\hline & & \multicolumn{2}{|c|}{$\begin{array}{c}\text { Wish to die } \\
n=145\end{array}$} & \multicolumn{2}{|c|}{$\begin{array}{c}\text { No wish to die } \\
n=2,666\end{array}$} & \multirow[b]{2}{*}{ Total (\%) } & \multirow[b]{2}{*}{$p$-value } \\
\hline & & $n$ & $\%$ & $n$ & $\%$ & & \\
\hline \multirow{2}{*}{ Gender } & Male & 28 & 19.3 & 804 & 30.2 & 29.6 & \\
\hline & Female & 117 & 80.7 & 1,862 & 69.8 & 70.4 & 0.005 \\
\hline \multirow{2}{*}{ Marital status } & With partner & 51 & 35.2 & 1,222 & 45.9 & 45.3 & \\
\hline & No partner & 94 & 64.8 & 1,443 & 54.1 & 54.7 & 0.012 \\
\hline \multirow{2}{*}{ Education } & $0-12$ years & 109 & 75.2 & 1,744 & 65.7 & 66.2 & \\
\hline & $\geq 13$ years & 36 & 24.8 & 912 & 34.3 & 33.8 & 0.018 \\
\hline \multirow{2}{*}{ Income CDN\$ } & $<25,000 \$$ & 75 & 55.6 & 1,077 & 45.1 & 45.7 & \\
\hline & $\geq 25,000 \$$ & 60 & 44.4 & 1,309 & 54.9 & 54.3 & 0.018 \\
\hline \multirow{3}{*}{ Depression $^{1}$} & Yes & 112 & 77.2 & 305 & 11.4 & 14.8 & \\
\hline & No & 33 & 22.8 & 2,361 & 88.6 & 85.2 & 0.001 \\
\hline & & Mean & $S D$ & Mean & $S D$ & Mean & \\
\hline \multicolumn{2}{|l|}{ Age } & 73.65 & 5.71 & 73.90 & 5.74 & 73.90 & 0.600 \\
\hline \multicolumn{2}{|c|}{ Self-rated physical health ${ }^{2}$} & 2.99 & 1.05 & 2.44 & 1.01 & 2.46 & 0.001 \\
\hline \multicolumn{2}{|c|}{$\mathrm{Nb}$. of chronic diseases } & 4.36 & 2.12 & 3.22 & 2.11 & 3.26 & 0.001 \\
\hline
\end{tabular}

Notes. ${ }^{1}$ Diagnosis of depression: major or minor; ${ }^{2} 1=$ Excellent, $5=$ Bad.

Table 1 also indicates that, compared to those without the wish to die, persons expressing these thoughts reported significantly more often a negative perception of their physical health, and a higher number of chronic illnesses. The majority $(77.2 \%, n=112)$ of those with wishes to die also had a diagnosis of depression (major or minor) compared to $11.4 \%$ in the group without the wish to die (see Table 2). It should be mentioned that among older adults with the wish to die, $17.2 \%$ suffered from some depressive symptoms, but did not meet sufficient diagnostic criteria to qualify for a depressive disorder. More precisely, $32.1 \%$ of the men with the wish to die had depressive symptoms but no diagnosis, while this percentage was $13.7 \%$ among women with the wish to die.

As shown in Table 3, nine chronic illnesses out of 15 were found significantly more often in elderly persons with wishes to die. For example, among those with the wish to die, $57.9 \%$ suffered from arthritis or rheumatism, while $37.2 \%$ of those without the wish to die suffered from the same affliction. It seems that painful chronic problems, like arthritis, back problem, migraine-headache, are more frequent in those with the wish to die, as well as those chronic illnesses that affect basic physiological needs, like digestive, respiratory, and urinary problems. 
Table 2

Depression Prevalence in Elderly Persons With and Without the Wish to Die

\begin{tabular}{lccccc}
\hline & \multicolumn{3}{c}{$\begin{array}{c}\text { Wish to die } \\
n=145\end{array}$} & \multicolumn{2}{c}{$\begin{array}{c}\text { No wish to die } \\
n=2,666\end{array}$} \\
\cline { 2 - 5 } & $n$ & $\%$ & $n$ & $\%$ & \\
Diagnosis of depression & & & & & \\
Major depression & 103 & 71.0 & 182 & 6.9 & 285 \\
Minor depression & 9 & 6.2 & 123 & 4.6 & 132 \\
Subtotal & 112 & 77.2 & 305 & 11.4 & 417 \\
Subclinical depression & 8 & 5.5 & 22 & 0.8 & 30 \\
Sympt., but no diagnosis & 25 & 17.2 & 227 & 8.5 & 252 \\
Subtotal & 145 & 100 & 554 & 20.8 & 699 \\
No symptoms & 0 & 0 & 2,112 & 79.2 & 2,112 \\
Total & 145 & 100 & 2,666 & 100 & 2,811 \\
\hline
\end{tabular}

Table 3

Presence of Chronic Illnesses in Participants With and Without the Wish to Die

\begin{tabular}{lccc}
\hline & Wish to die & No wish to die \\
& $n=145$ & $n=2,666$ & $p$-value \\
\cline { 2 - 4 } & $\%$ & $\%$ & 0.603 \\
Anemia & 6.2 & 5.2 & 0.001 \\
Arthritis/Rheumatism & 57.9 & 37.2 & 0.001 \\
Back problem & 39.3 & 22.7 & 0.936 \\
Blood pressure & 53.1 & 52.8 & 0.315 \\
Cholesterol & 42.8 & 38.6 & 0.928 \\
Diabetes & 15.2 & 15.5 & 0.001 \\
Digestive problem & 27.6 & 16.4 & 0.042 \\
Endocrine problem & 26.9 & 19.9 & 0.362 \\
Heart problem & 31.0 & 27.6 & 0.003 \\
Kidney/Urinary/Prostateproblem & 21.4 & 12.9 & 0.090 \\
Liver problem & 4.8 & 2.5 & 0.001 \\
Migraine/headaches & 13.8 & 6.6 & 0.001 \\
Respiratory problem & 27.6 & 14.0 & 0.005 \\
Skin problem & 20.3 & 12.3 & 0.017 \\
Visual problem (glaucoma cataract) & 41.4 & 31.9 & \\
\hline
\end{tabular}

Since certain types of chronic illnesses affect women and men differently, a logistic regression (see Table 4), controlling for gender, revealed that three of the nine chronic illnesses were significantly associated with increased odds of wishes to die: arthritis/rheumatism $\left(\mathrm{OR}=1.72, \mathrm{CI}_{95 \%}\right.$ : 1.19-2.48), respiratory problems $(\mathrm{OR}=$ $\left.1.85, \mathrm{CI}_{95 \%}: 1.24-2.75\right)$, and kidney/urinary/prostate problems ( $\left.\mathrm{OR}=1.76, \mathrm{CI}_{95 \%}: 1.13-2.74\right)$. Elderly persons suffering from these chronic illnesses were almost two times more likely to have the wish to die. This model explains $7.3 \%$ of the variance in the wish to die $\left(R^{2}\right.$ Nagelkerke).

Next, a three-step hierarchical logistic regression analysis (see Table 5) was performed with the wish to die as the dependent variable. Gender was entered at step 1 of the regression to control for this demographic variable. Depression was entered at step 2, because this variable is usually an important predictor of the wish to die. Chronic illnesses were entered in step 3. Since comorbidity is a frequent situation in old age, it was decided not to enter all nine illnesses in this last regression, but only those that were significant when gender was 
controlled. Therefore, the three chronic illnesses (arthritic, respiratory, and kidney/urinary/prostate diseases) were entered simultaneously in step 3 to see if they could add to the prediction of the wish to die when depression and gender were controlled. The two-step model, which included only gender and depression, was significant $\left(\chi^{2}=308.43, p<0.001\right.$ with $\left.d f=2\right)$ and explained $31.2 \%$ of the variance of the wish to die. As in other studies, depression was an important significant associated factor $\left(\mathrm{OR}=23.77, \mathrm{CI}_{95 \%}\right.$ : 15.7-36.0). Finally, the full model (see Table 5) revealed that two out of the three chronic illnesses remained significantly associated with the wish to die, when controlling for depression and gender: arthritis/rheumatism $(\mathrm{OR}=1.64$, $\left.\mathrm{CI}_{95 \%}: 1.11-2.40\right)$ and kidney/urinary/prostate problems ( $\left.\mathrm{OR}=1.85, \mathrm{CI}_{95 \%}: 1.14-3.01\right)$. The addition of these chronic illnesses to the model explained $1.7 \%$ of the variance in the wish to die and was statistically significant $\left(\chi^{2}=18.32, p<0.001\right.$ with $\left.d f=3\right)$.

Table 4

Risk to Present Wishes to Die According to Gender and Types of Chronic Illnesses

\begin{tabular}{|c|c|c|c|c|}
\hline & & \multicolumn{3}{|c|}{ Probability for the wish to die } \\
\hline & & OR & $\mathrm{CI}_{95 \%}$ & $p$-value \\
\hline \multirow{2}{*}{ Gender } & Male & $*$ & & \\
\hline & Female & 1.57 & $0.99-2.49$ & 0.053 \\
\hline \multicolumn{2}{|c|}{ Arthritis/Rheumatism } & 1.72 & $1.19-2.48$ & 0.004 \\
\hline \multicolumn{2}{|c|}{ Back problem } & 1.34 & $0.91-1.96$ & 0.140 \\
\hline \multicolumn{2}{|c|}{ Digestive problem } & 1.46 & $0.98-2.17$ & 0.060 \\
\hline \multicolumn{2}{|c|}{ Endocrine problem } & 1.27 & $0.85-1.89$ & 0.240 \\
\hline \multicolumn{2}{|c|}{ Kidney/Urinary/Prostate problem } & 1.76 & $1.13-2.74$ & 0.010 \\
\hline \multicolumn{2}{|c|}{ Migraine/Headaches } & 1.57 & $0.93-2.64$ & 0.090 \\
\hline \multicolumn{2}{|c|}{ Respiratory problem } & 1.85 & $1.24-2.75$ & 0.003 \\
\hline \multicolumn{2}{|c|}{ Skin problem } & 1.46 & $0.94-2.25$ & 0.090 \\
\hline \multicolumn{2}{|c|}{ Visual problem } & 1.15 & $0.81-1.64$ & 0.440 \\
\hline
\end{tabular}

Table 5

Risk to Present Wishes to Die According to Gender, Depression, and Types of Chronic Illnesses

\begin{tabular}{|c|c|c|c|c|}
\hline & & \multicolumn{3}{|c|}{ Probability for the wish to die } \\
\hline & & OR & $\mathrm{CI}_{95 \%}$ & $p$-value \\
\hline \multirow{2}{*}{ Gender } & Male & $*$ & & \\
\hline & Female & 1.08 & $0.66-1.76$ & 0.760 \\
\hline \multirow{2}{*}{ Depression $^{1}$} & Yes & 23.77 & $15.7-36.0$ & 0.001 \\
\hline & No & $*$ & & \\
\hline \multicolumn{2}{|c|}{ Arthritis/Rheumatism } & 1.64 & $1.11-2.40$ & 0.010 \\
\hline \multicolumn{2}{|c|}{ Respiratory problem } & 1.53 & $0.99-2.37$ & 0.053 \\
\hline \multicolumn{2}{|c|}{ Urinary/Prostate/Kidney problem } & 1.85 & $1.14-3.01$ & 0.010 \\
\hline
\end{tabular}

Note. ${ }^{1}$ Diagnosis of depression: major or minor.

\section{Discussion}

The goal of the research was to study the annual prevalence of the wish to die in older adults living in the community. Results indicated a prevalence of $5.2 \%$ in our representative sample of 2,811 older adults. This rate confirms data from previous studies that found a prevalence rate between $4 \%$ and $7 \%$ for various time frames: past week (Barnow \& Linden, 1997; Jorm et al., 1995), previous month (Ayalon \& Shiovitz-Ezra, 2011; 
Scocco \& De Leo, 2002), and one year (Kim et al., 2006). As in other studies (Barnow \& Linden, 1997; Scocco et al., 2001), significantly more women than men expressed the wish to die. It is possible that women express more easily than men their wish to die, as well as other forms of psychological pain (depression), as part of a help-seeking behavior (Scocco et al., 2001). The expression of their distress at the beginning of the suicidal process might be a useful coping mechanism to prevent future suicidal behaviors. On the other hand, it should be noted that one out of three men (32.1\%) with the wish to die did not meet sufficient diagnostic criteria to qualify for a depressive disorder. Results from qualitative interviews with 30 clinicians involved in a management program for late-life depression, could explain this observation (Hinton, Zweifach, Oishi, Tang, \& Unützer, 2006). According to the clinicians, older men endorsed core symptoms of depression, like feeling down and lack of interest, less often than older women. They were expressing their distress differently than women, through somatic symptoms, anger, or interpersonal conflicts, behaviors that are not part of the list of criteria for depression. Therefore, other variables rather than clinical diagnosis should be included in the complex evaluation of psychological distress, if one wants an opportunity to detect and help elderly men who wish to die. Hinton et al. (2006) also indicated that many men were concealing their distress to avoid mental illness stigma and feelings of shame, and because asking for help would undermine their image of masculinity. The attitudes of older men could explain why they are particularly less inclined to seek mental health services (Drapeau et al., 2009). Further research is needed on the wish to die among men, especially on their way of expressing distress.

Although many chronic illnesses ( 9 out of 15) were found significantly more often in older adults with the wish to die, painful diseases and those that affect basic physiological needs (eating, breathing, eliminating) were particularly important associated factors. These results are similar to those that found that chronic pain conditions (arthritis, back problems, migraine) significantly contributed to suicidal ideation (Ratcliffe, Enns, Belik, \& Sareen, 2008; Tang \& Crane, 2006) or that breathing disorders and urinary incontinence were unique contributing factors of suicidality when depression was controlled in a multivariate analysis (Juurlink et al., 2004; Quan et al., 2002; Rurup et al., 2011). Mental state assessment of older adults suffering from chronic pain or from diseases that significantly decreases their QOL (quality of life) seems essential for preventive interventions. Indeed, Kunik et al. (2005) observed a high prevalence (65\%) of depression and/or anxiety in veterans with obstructive pulmonary disease, but that only a third of them were being treated for those mental disorders.

In our study, two chronic diseases remained significantly associated with the wish to die when controlling for gender and depression: arthritis/rheumatism and urinary/kidney/prostate problems. These two types of chronic illnesses are frequently related to functional limitations and reduce the QOL. By hindering the capacity to perform activities of daily living or to realize meaningful activities, functional limitations can induce discouragement and depressive affects, as well as the wish to die (Mellqvist Fässberg, Ôstling, Bäckman, Skoog, \& Waern, 2014). Also, urinary/prostate diseases can cause incontinence or sexual dysfunction, and some older patients with chronic renal failure might have to submit to dialysis, all of which can seriously influence QOL and trigger the wish to die in individuals who cannot accept those conditions (Rurup, Deeg et al., 2011; Rurup, Pasman et al., 2011).

Our results showed that the full model, including gender, depression, and three chronic illnesses explained $32.9 \%$ of the variance in the wish to die. Nonetheless, there was still $67.1 \%$ unaccounted for. Many other variables should be studied in order to understand the relations between chronic illnesses and the wish to die. 
For example, painful chronic illness could cause insomnia which has been associated with suicide in other studies (Wojnar, Ilgen, Wojnar, McCammon, Valenstein, \& Brower, 2009). Chronic illnesses also have less hope for a cure and could provoke feelings of helplessness and hopelessness. These emotions might be important variables that mediate the relations between chronic illness, physical pain, and the wish to die, while insomnia caused by pain probably removes any possibility to escape from this unbearable situation. Chronic illness could also generate perceived burdensomeness, which might be an important mediating variable of the variance of the wish to die in older adults living in the community. In fact, other studies have shown that feeling as a burden to their family mediated the relation between depression and suicidal ideation (Cukrowicz, Cheavens, Van Orden, Ragain, \& Cook, 2011; Jahn \& Cukrowicz, 2011; Jahn, Cukrowicz, Linton, \& Prabhu, 2011).

Each illness has specific symptoms which are experienced differently by each individual. Future studies should look beyond the type of illness. Evaluation of certain types of symptoms might be more relevant to the understanding of the relationship between illness and the wish to die and might be an essential part of the investigation of the distress of elderly patients. Any type of illness that affects the QOL and the ability to realize meaningful activities can lead to depression. Depression is the common denominator between all types of illnesses and losses.

Doctors and health professionals should be aware of the impact of pain and insomnia on the wish to die and identify specialized resources to treat them rapidly and efficiently (Bain, 2006; Bloom et al., 2009; McGuire, Nicholas, Asghari, Wood, \& Main, 2014). Since painful physical symptoms are a significant predictor of help-seeking (Bonnewyn et al., 2009), and because older adults might report more easily sleep disorders than depression to their family doctors, attention should be directed to those health-related factors that may be remediable. Moreover, referrals to social, community, and environmental resources, which can improve older adults' life conditions and assist in reducing the impact of disability in their life, might help decrease the wish to die (Erlangsen et al., 2011). Psychological help that can improve coping abilities that alleviate the stress related to these difficulties could also be an interesting intervention strategy (Erlangsen et al., 2011; Marusic \& Goodwin, 2006). Nonetheless, what seems important is to develop positive attitudes toward living to compensate for the negative aspects of living and the positive aspects of dying (Rurup, Deeg et al., 2011; Rurup, Pasman et al., 2011). The restoration of the wish to live could be done with a mental health promotion program that support the realization of personal projects that give meaning to the older adult's life, even when disability restricts one's possibility (Freund \& Baltes, 2002; Lapierre, Dubé, Bouffard, \& Alain, 2007). Innovative strategies that increase empowerment, coping and adaptive behavior, resilience, flexibility, social skills, self-esteem, sense of belonging, and hope, could help elderly persons face the challenges created by chronic illness and improve protective factors against the wish to die (Lapierre et al., 2007; 2011).

Since the expression of a wish to die could be the first step into the process toward suicidal behavior, the results from this study constitute an interesting contribution to the development of knowledge for preventive actions. The results suggest that the wish to die or its correlates should be screened when health professionals encounter elderly persons suffering from chronic diseases that affect the QOL. They should ask the following question, which is widely used by suicide prevention hotlines to assess suicidal intent (Joiner et al. 2007): "With the difficulties you are experiencing currently, do you wish for death?" This question encourages discussion on the problems that the older adult is facing and shows that the health professional is open to hear about his/her wish to die (Kjølseth \& Ekeberg, 2012). 
The major strength of this study is that elderly participants were interviewed directly about their wish to die, while case-control studies on suicide have to rely on the perception of informants close to the deceased older adult. Interestingly, both methods lead to similar results about the association between suicidality and physical illness. Another strength was that our survey used a representative and probabilistic sample (the response rate was very good: $76.5 \%$ ) to understand the wish to die in both genders.

Nonetheless, current findings should be interpreted with the following limitations in mind. First, like other research in the field (Jorm et al., 1995; Kim et al., 2006; Scocco et al., 2001), our survey relied on a single self-report item, that was simply answered by yes or no, to determine the presence of the wish to die. To our knowledge, no rigorous measure exists to assess the wish to die (Rurup, Deeg et al., 2011; Rurup, Pasman et al., 2011). Second, since the objective of the survey was to document the annual prevalence of psychiatric disorders in the older adult population, questions were asked about the occurrence, during the course of the previous year, of various symptoms, including the wish to die, while the survey listed the participants' current chronic illnesses. The temporal relationship between the chronic medical condition and the wish to die is unknown. Also, in this retrospective study, participants could have recall bias about past thoughts of death and feelings. Past wishes to die might not be directly related to current chronic diseases, and the cross-sectional nature of the data precludes determination of causality. Third, our survey on mental disorders did not evaluate the presence of pain and common co-occurring disability which could also have a significant impact on the wish to die. Finally, all studies on the association between illness and suicidality consider various kinds of physical disorders, with only a few of them in common. In our survey, the selected 15 categories of chronic illness also covered various diseases, and the associations with the wish to die are limited to those general categories and cannot be related to a specific affliction. Because of the array of ailments and the difficulty in establishing a common list for research purposes, we would not recommend looking at precise illnesses in subsequent research. Besides, it would considerably reduce the number of participants in each condition. It would be preferable to look at certain types of symptoms (types of pain, incontinence, loss of appetite, difficulty breathing, swelling, etc.) and their impact on the QOL of older adults, in order to study the variance in the wish to die.

Our study was centered on the wish to die of older adults living in the community. New research should focus on institutionalized elderly persons, especially because their living conditions and health status could make them wish for death and at risk for future suicidal thoughts (Scocco, Fantoni, Rapattoni, de Girolamo, \& Pavan, 2009).

\section{Conclusion}

More research investigating the wish to die is necessary, since early detection is essential to prevent attempted and completed suicide. Most preventive programs focus on the identification of depression as a mean to prevent suicide (Lapierre et al., 2011), but this needs specialized clinical abilities. Our study suggests that there are other related variables that could help in the early detection of psychological distress by those who are in contact with the aged population. By giving rigorous attention to the stress produced by chronic illnesses, the type of symptoms, the impact on life conditions, feelings of helplessness or hopelessness, and perceived burdensomeness, professionals would have a unique opportunity to detect at risk individuals and refer them to resources that can help them improve their QOL and well-being, and incidentally, restore the desire to live (Erlangsen et al., 2011; Lapierre et al., 2011). 


\section{References}

Awata, S., Seki, T., Koizumi, Y., Sato, S., Hozawa, A., Omori, K., ... Tsuji, I. (2005). Factors associated with suicidal ideation in an elderly urban Japanese population: A community-based, cross-sectional study. Psychiatry and Clinical Neurosciences, 59(3), 327-336.

Ayalon, L., \& Shiovitz-Ezra, S. (2011). The relationship between loneliness and passive death wishes in the second half of life. International Psychogeriatrics, 23, 1677-1685.

Bain, K. (2006). Management of chronic insomnia in elderly persons. American Journal of Geriatric Pharmacotherapy, 4(2), 168-192.

Barnow, S., \& Linden, M. (1997). Suicidality and tiredness of life among very old persons: Results from the Berlin Aging Study (BASE). Archives of Suicide Research, 3, 171-182.

Barnow, S. S., \& Linden, M. M. (2000). Epidemiology and psychiatric morbidity of suicidal ideation among the elderly. Crisis: The Journal of Crisis Intervention and Suicide Prevention, 21(4), 171-180.

Bloom, H. et al. (2009). Evidence-based recommendations for the assessment and management of sleep disorders in older persons. Journal of the American Geriatrics Society, 57(5), 761-789.

Bonnewyn, A. A., Katona, C. C., Bruffaerts, R. R., Haro, J. M., de Graaf, R. R., Alonso, J. J., \& Demyttenaere, K. K. (2009). Pain and depression in older people: Comorbidity and patterns of help seeking. Journal of Affective Disorders, 117(3), 193-196.

Crum, R. M., Anthony, J. C., Bassett, S. S., \& Folstein, M. F. (1993). Population-based norms for the mini-mental state examination by age and educational level. Journal of the American Medical Association, 269, 2386-2391.

Cukrowicz, K. C., Cheavens, J. S., Van Orden, K. A., Ragain, R., \& Cook, R. L. (2011). Perceived burdensomeness and suicide ideation in older adults. Psychology and Aging, 26(2), 331-338.

De Leo, D., Cerin, E., Spathonis, K., \& Burgis, S. (2005). Lifetime risk of suicide ideation and attempts in an Australian community: Prevalence, suicidal process, and help-seeking behaviour. Journal of Affective Disorders, 86, 215-224.

Drapeau, A., Boyer, R., \& Lesage, A. (2009). The influence of social anchorage on the gender difference in the use of mental health services. The Journal of Behavioral Health Services \& Research, 36(3), 372-384.

Erlangsen, A. et al. (2011). Key considerations for preventing suicide in older adults: Consensus opinions of an expert panel. Crisis: The Journal of Crisis Intervention and Suicide Prevention, 32(2), 106-109.

Fiksenbaum, L., Greenglass, E., \& Eaton, J. (2006). Perceived social support, hassles, and coping among the elderly. Journal of Applied Gerontology, 25(1), 17-30.

Folstein, M. F., Folstein, S. E., \& McHugh, P. R. (1975). "Mini-mental state": A practical method for grading the cognitive state of patients for the clinician. Journal of Psychiatric Research, 12, 189-198.

Freund, A. M. (2008). Successful aging as management of resources: The role of selection, and optimization, and compensation. Research on Human Development, 5, 94-106.

Freund, A. M., \& Baltes, P. B. (2002). The adaptiveness of selection, optimization, and compensation as strategies of life management: Evidence from a preference study on proverbs. The Journals of Gerontology: Series B: Psychological Sciences and Social Sciences, 57B(5), P426-P434.

Harwood, D. M. J., Hawton, K., Hope, T., Harriss, L., \& Jacoby, R. (2006). Life problems and physical illness as risk factors for suicide in older adults: A descriptive and case-control study. Psychological Medicine, 36, 1265-1274.

Heisel, M. J., Duberstein, P. R., Talbot, N. L., King, D. A., \& Tu, X. M. (2009). Adapting interpersonal psychotherapy for older adults at risk for suicide: Preliminary findings. Professional Psychology: Research and Practice, 40, 156-164.

Hinton, L., Zweifach, M., Oishi, S., Tang, L., \& Unützer, J. (2006). Gender disparities in the treatment of late-life depression: Qualitative and quantitative findings from the IMPACT trial. The American Journal of Geriatric Psychiatry, 14(10), 884-892.

Im, J., Choi, S., Hong, D., Seo, H., Park, S., \& Hong, J. (2011). Proximal risk factors and suicide methods among suicide completers from national suicide mortality data 2004-2006 in Korea. Comprehensive Psychiatry, 52(3), 231-237.

Jahn, D. R., \& Cukrowicz, K. C. (2011). The impact of the nature of relationships on perceived burdensomeness and suicide ideation in a community sample of older adults. Suicide and Life-Threatening Behavior, 41(6), 635-649.

Jahn, D. R., Cukrowicz, K. C., Linton, K., \& Prabhu, F. (2011). The mediating effect of perceived burdensomeness on the relation between depressive symptoms and suicide ideation in a community sample of older adults. Aging \& Mental Health, 15(2), 214-220. 
Joiner, T. et al. (2007). Establishing standards for the assessment of suicide risk among callers to the National Suicide Prevention Lifeline. Suicide and Life-Threatening Behavior, 37(3), 353-365.

Jorm, A., Henderson, A., Scott, R., Korten, A., Christensen, H., \& Mackinnon, A. (1995). Factors associated with the wish to die in elderly people. Age and Ageing, 24(5), 389-392.

Juurlink, D., Herrmann, N., Szalai, J., Kopp, A., \& Redelmeier, D. (2004). Medical illness and the risk of suicide in the elderly. Archives of Internal Medicine, 164(11), 1179-1184.

Kim, Y., Bogner, H., Brown, G., \& Gallo, J. (2006). Chronic medical conditions and wishes to die among older primary care patients. International Journal of Psychiatry in Medicine, 36, 183-198.

Kjølseth, L., \& Ekeberg, Ø. (2012). When elderly people give warning of suicide. International Psychogeriatrics, 24(9), 1393-1401.

Kjølseth, L., Ekeberg, Ø., \& Steihaug, S. (2010). Why suicide? Elderly people who committed suicide and their experience of life in the period before their death. International Psychogeriatrics, 22(2), 209-218.

Kunik, M. et al. (2005). Surprisingly high prevalence of anxiety and depression in chronic breathing disorders. Chest, 127(4), 1205-1211.

Lapierre, S., Boyer, R., Desjardins, S., Dubé, M., Lorrain, D., Préville, M., \& Brassard, J. (2012). Daily hassles, physical illness, and sleep problems in older adults with wishes to die. International Psychogeriatrics, 24(2), 243-252.

Lapierre, S., Erlangsen, A., Waern, M., De Leo, D., Oyama, H., Scocco, P., ... Quinnett, P. (2011). A systematic review of elderly suicide prevention programs. Crisis: The Journal of Crisis Intervention and Suicide Prevention, 32(2), 88-98.

Lapierre, S., Dubé, M., Bouffard, L., \& Alain, M. (2007). Addressing suicidal ideations through the realization of meaningful personal goals. Crisis: The Journal of Crisis Intervention and Suicide Prevention, 28(1), 16-25.

Linden, M., \& Barnow, S. (1997). The wish to die in very old persons near the end of life: A psychiatric problem? Results from the Berlin Aging Study. International Psychogeriatrics, 9, 291-307.

Marušič, A. (2004). Toward a new definition of suicidality? Are we prone to Fregoli's illusion? Crisis: The Journal of Crisis Intervention and Suicide Prevention, 25(4), 145-146.

Marušič, A., \& Goodwin, R. D. (2006). Suicidal and deliberate self-harm ideation among patients with physical illness: The role of coping styles. Suicide and Life-Threatening Behavior, 36(3), 323-328.

McGuire, B. E., Nicholas, M. K., Asghari, A., Wood, B. M., \& Main, C. J. (2014). The effectiveness of psychological treatments for chronic pain in older adults: Cautious optimism and an agenda for research. Current Opinion in Psychiatry, 27(5), 380-384.

Meeks, T. W., Dunn, L., Kim, D., Golshan, S., Sewell, D., Atkinson, J., \& Lebowitz, B. (2008). Chronic pain and depression among geriatric psychiatry inpatients. International Journal of Geriatric Psychiatry, 23, 637-642.

Mellqvist Fässberg, M., Ôstling, S., Bäckman, K., Skoog, I., \& Waern, M. (August, 2014). Functional disability and death wishes in older Europeans: Results from the EIRODEP concerted action. Poster presented at the 15th European Symposium on Suicide and Suicidal Behavior, Tallinn, Estonia.

O’Connell, H., Chin, A. V., Cunningham, C., \& Lawlor, B. A. (2004). Recent developments: Suicide in older people. British Medical Journal, 329(7471), 895-899.

Préville, M., Boyer, R., Grenier, S., Dubé, M., Voyer, P., Punti, R., ... ESA Study. (2008). The epidemiology of psychiatric disorders in the Quebec older adult population. Canadian Journal of Psychiatry, 53, 822-832.

Préville, M., Hébert, R., Boyer, R., Bravo, G., \& Seguin, M. (2005). Physical health and mental disorder in elderly suicide: A case-control study. Aging \& Mental Health, 9(6), 576-584.

Quan, H., Arboleda-Florez, J., Fick, G. H., Stuart, H. L., \& Love, E. J. (2002). Association between physical illness and suicide among the elderly. Social Psychiatry and Psychiatric Epidemiology, 37, 190-197.

Rao, R., Dening, T., Brayne, C., \& Huppert, F. A. (1997). Attitudes toward death: A community study of octogenarians and nonagenarians. International Psychogeriatrics, 9(2), 213-221.

Ratcliffe, G., Enns, M., Belik, S., \& Sareen, J. (2008). Chronic pain conditions and suicidal ideation and suicide attempts: An epidemiologic perspective. The Clinical Journal of Pain, 24(3), 204-210.

Rubenowitz, E., Waern, M., Wilhelmson, K., \& Allebeck, P. (2001). Life events and psychosocial factors in elderly suicides: A case-control study. Psychological Medicine, 31(7), 1193-1202.

Rurup, M. L., Deeg, D. J., Poppelaars, J. L., Kerkhof, A. J., \& Onwuteaka-Philipsen, B. D. (2011). Wishes to die in older people: A quantitative study of prevalence and associated factors. Crisis, 32, 194-203.

Rurup, M. L., Pasman, H. R., Goedhart, J., Deeg, D. J., Kerkhof, A. J., \& Onwuteaka-Philipsen, B. D. (2011). Understanding why older people develop a wish to die: A qualitative interview study. Crisis, 32, 204-216. 
Saïas, T., Beck, F., Bodard, J., Guignard, R., \& Roscoät, E. (2012). Social participation, social environment and death ideations in later life. Plos ONE, 7(10), Oct. 8, ArtID e46723.

Scocco, P., \& De Leo, D. (2002). One-year prevalence of death thoughts, suicide ideation and behaviours in an elderly population. International Journal of Geriatric Psychiatry, 17, 842-846.

Scocco, P., Fantoni, G., Rapattoni, M., de Girolamo, G., \& Pavan, L. (2009). Death ideas, suicidal thoughts, and plans among nursing home residents. Journal of Geriatric Psychiatry and Neurology, 22(2), 141-148.

Scocco, P., Meneghel, G., Caon, F., Buono, M., \& De Leo, D. (2001). Death ideation and its correlates: Survey of an over-65-year-old population. Journal of Nervous and Mental Disease, 189, 210-218.

Skoog, I., Aevarsson, O., Beskow, J., Larsson, L., Palsson, S., Waern, M., \& Ostling, S. (1996). Suicidal feelings in a population of nondemented 85-years-olds. American Journal of Psychiatry, 153, 1015-1020.

Tang, N. Y., \& Crane, C. (2006). Suicidality in chronic pain: A review of the prevalence, risk factors and psychological links. Psychological Medicine, 36(5), 575-586.

Vasiliadis, H., Gagné, S., \& Préville, M. (2012). Gender differences in determinants of suicidal ideation in French-speaking community living elderly in Canada. International Psychogeriatrics, 24(12), 2019-2026.

Waern, M., Rubenowitz, E. E., Runeson, B. B., Skoog, I. I., Wilhelmson, K. K., \& Allebeck, P. P. (2002). Burden of illness and suicide in elderly people: Case-control study. British Medical Journal, 324(7350), 1355-1357.

Waern, M., Rubenowitz, E., \& Wilhelmson, K. (2003). Predictors of suicide in the old elderly. Gerontology, 49, 328-334.

Wojnar, M., Ilgen, M., Wojnar, J., McCammon, R., Valenstein, M., \& Brower, K. (2009). Sleep problems and suicidality in the National Comorbidity Survey Replication. Journal of Psychiatric Research, 43, 526-531. 